\title{
Ensamblaje del Sistema de Información Documental en la producción de los noticiarios televisivos.
}

\author{
Jorge Caldera-Serrano
}

\begin{abstract}
Resumen
Se muestra la estructura lógica y utilidad de un Sistema de Información Documental encuadrado en el marco de las organizaciones empresariales televisivas. Para describir los procesos de utilización de los diferentes subsistemas de documentación en las televisiones (audiovisual, textual, sonoro y fotográfico) se lleva a cabo un recorrido sobre las etapas de creación de una noticia televisiva, indicando en qué momento y de qué manera la documentación es parte de la cadena de montaje de la información que posteriormente será emitida por la cadena.
\end{abstract}

\section{Palabras clave}

Television archives, Information Management Systems, Television, News, Multimedia Documentation

\section{Assembly of the Information Management System in television newscast production}

\begin{abstract}
The paper presents the logical structure and uses of the Document Information System in business television organizations. In order to describe the processes involved in the different documentation subsystems in television, the creation of a news item is walked through, indicating when and how each subsystem plays a part in the assembly line of the final broadcast product.
\end{abstract}

Keywords

Television archives, Information Management Systems, Television, News, Multimedia Documentation

http://dx.doi,org/10,5209/rev_CDMU,2013,v24,46280 


\section{BINOMIO TELEVISIÓN/DOCUMENTACIÓN.}

Han pasado muchos años desde que nuestros antepasados pintaban sobre piedra aquello que deseaban conseguir, intentando llevar a cabo una comunicación con alguna divinidad. Sin embargo, en la actualidad la comunicación cuenta con modelos más fáciles y habituales para la interconexión entre dos individuos y/o masas. La Historia de la Humanidad está indisolublemente unida a la evolución y a la revolución tecnológica, y la comunicación es de los aspectos que más relación ha tenido con dicha evolución de la ciencia y de la técnica, pasando de los primeros periódicos a los impresionantes satélites de comunicaciones. La televisión se ha constituido en una de las grandes revoluciones en la forma de comunicar, revolución que se extrapola tanto a los métodos de informar como a los modelos de producción y difusión.

Pensar en información y entretenimiento en la sociedad actual en la que el homo videns y el homo digitalis han desbancando por completo a sus antecesores, es hablar de Televisión como elemento democratizador, universal y familiar. La televisión ha logrado llevar a cabo la antigua idea de McLuhan (1962) en una realidad, ya que todos formamos parte de la "aldea televisiva", con sus ventajas pero también con sus inconvenientes.

\begin{tabular}{|l|l|l|l}
\hline Homo Sapiens & Homo & Homo videns & Homo digitalis
\end{tabular}

typographicus

Este cuarto poder necesita contar con estructuras estables y costosas para poder producir, conservar y difundir la información, y será en este momento donde la Comunicación se da la mano con las Ciencias de la Documentación. La información es la unidad de trabajo tanto para las Ciencias de la Comunicación como para la Documentación, mientras que la primera accede y selecciona atendiendo a sus peculiaridades informativas, la Documentación conserva, analiza y difunde esa misma información atendiendo a criterios claramente documentales, pensando siempre en los periodistas como usuarios de estos servicios.

Debe quedar claro que en la estructura televisiva la existencia de los departamentos de documentación cuenta con sentido en sí mismo desde el momento que están y se conforman para responder a las solicitudes de los periodistas, los cuales son principio y fin de la implementación y diseño de los sistemas documentales en las empresas audiovisuales televisivas.

Parece incuestionable la importancia que ha tomado en nuestra sociedad la gestión de la información por medio del control de la documentación, tanto es así que se toma como pieza fundamental en el desarrollo de cualquier actividad humana tanto en la fase de implementación y desarrollo, como durante el ejercicio de la actividad profesional.

La Documentación ha dejado de ser un mero acompañamiento en las organizaciones y en las investigaciones científicas, siendo piedra angular en el desarrollo de dichas actividades. 
El rol de los gestores de la información ha evolucionado a "banqueros" del nuevo "capital": el conocimiento. Cualquier empresa cuenta con la documentación como un activo empresarial más, un activo empresarial que cuenta con una doble vertiente: activo intelectual y activo económico.

La información también cuenta con un valor económico explotacional, aunque no sea la principal función en la mayor parte de las organizaciones (aparte de las empresas de gestión de la información). Parece evidente que sí cuenta con el valor patrimonial y de registro del conocimiento generado por la entidad a la que sirve. Este valor patrimonial no mengua su valía como explotación diaria, ofreciendo información documentada a los profesionales de las instituciones, siendo en muchos casos el principal acicate de "los banqueros" de la información.

La tendencia de las Ciencias de la Documentación a entenderse dentro del marco del Information Management no hace sino apostar por la información como activo tanto para la toma de decisiones en las organizaciones como para el desarrollo continuado de su actividad empresarial.

Los medios de comunicación, denominados el cuarto poder, cuentan con la necesidad de basarse y apoyarse en el quinto poder: el control y acceso a la información. El acceso a la información/documentación es un privilegio de las empresas que habrán de gestionar con sumo cuidado para el posterior desarrollo empresarial.

Los medios de comunicación no son empresas diferentes a otras, por lo que la información cuenta con la valía de activo empresarial desde los diferentes puntos de vista mencionados, además de potenciarse como motor de desarrollo de la actividad cotidiana en las empresas comunicativas. No puede ni debe entenderse los servicios de documentación sino es para ofrecer servicios a sus usuarios: los periodistas. En el comienzo de los servicios de documentación de las empresas comunicativas no se contaba con la información ni como activo económico ni como patrimonio, sino como fórmula válida de acceder a información para generar posteriormente productos informativos.

\section{SISTEMA DE INFORMACIÓN DOCUMENTAL EN LA TV}

La gestión de la información en el marco de las empresas se encuentra enmarcado en la tendencia teórica y conceptual del Information Management Systems, donde la información es tomada como un activo empresarial a la altura de los recursos económicos y los recursos humanos, como elemento integrador y vertebrador del círculo productivo de información-dinero-poder. Por lo tanto, teniendo presente la documentación como activo empresarial y como factor de desarrollo parece complicado su interrelación con otras unidades del mismo campo al considerarse competencia empresarial.

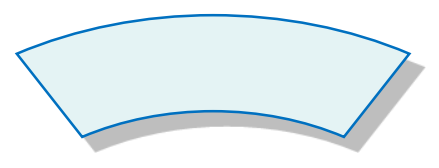

Información Dinero

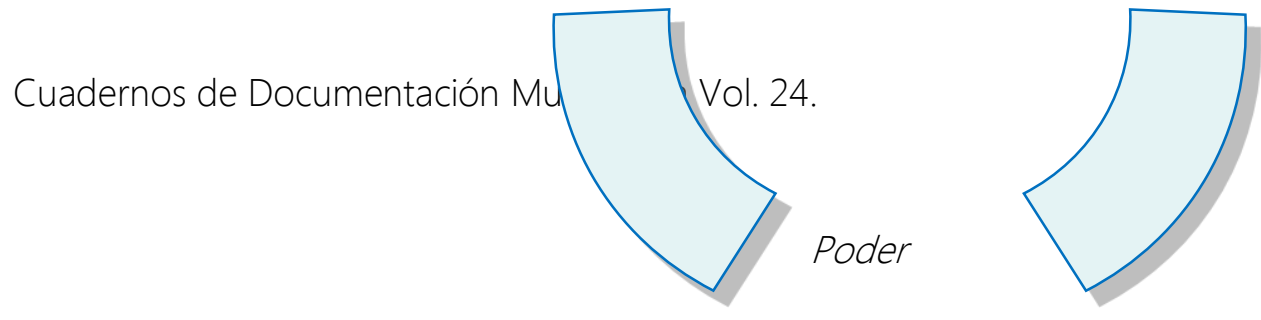




\section{Gráfico 1}

La realidad nos hace patente dicha hipótesis ya que la relación entre las cadenas es mínima en el ámbito de la coordinación y cooperación investigadora, y todo ello partiendo de una realidad, la existencia de organizaciones supranacionales que coordinan dichas empresas televisivas. La European Broadcasting Union (url://www.ebu.ch/index.php) y la Internacional Federation of Television Archives (url://www.fiatifta.org/) son un claro ejemplo de entidades supranacionales con escasa presencia en el desarrollo de investigaciones relevantes de un calado amplio entre las empresas audiovisuales.

La forma de entender la gestión de la documentación debe enmarcase en la teoría sistémica, que entiende a las Ciencias de la Documentación en el marco del IMS, integrando al servicio documental y los procesos desarrollados en éstos como un elemento más depłndeistema mayor que cuentan con el fin de lograr los objetivos empresariales. La teoría de sistemas es un pilar fundamental para la teoría de los sistemas de información y de la organización, las cuales fundamentan y dan sentido a las Ciencias de la Documentación.

En el ámbito español Lluís Codina (1994) definió Sistema de Información Documental señalando que éstos obtienen, almacenan, recuperan y distribuyen la información registrada en un depósito o red de información, y que para ello es necesaria la representación del contenido acorde con los usuarios del sistema.

Los sistemas de información documental deben adaptarse al marco empresarial en el que se mueven y trabajan, adaptándose a las posibilidades económicas y estructurales de la empresa en la cual esté encuadrada. Uno de los primeros puntos que debe tenerse en cuenta es la potencial división estructural entre subsistema administrativo y subsistema documental.

Uno de los nuevos contextos en los que ha de moverse los SID en los medios audiovisuales es el inminente proceso de digitalización, proceso ya superado en muchas cadenas derivado de la mayor y mejor accesibilidad a la información gestionada por los SID. Las intranets se presentan como la herramienta más importante para la interrelación entre los SID y los usuarios, agilizando el acceso y potenciando el intercambio de conocimientos.

De todas maneras, este proceso de digitalización retrospectiva sigue siendo uno de las principales amenazas en las televisiones, derivado de la complejidad de la digitalización de material audiovisual, complejidad entendida desde el punto de vista tecnológico y de equipamiento técnico. Parte de los sistemas de información, como la gestión de la documentación fotográfica, es de los primeros servicios digitalizados por su facilidad y escasos requerimientos informáticos. Para la migración del material audiovisual los requerimientos y componentes tanto de software como de hardware se complican y se encarecen.

Independientemente de todos los problemas que pudieran preverse o existan en el proceso de digitalización, abanderar una postura favorable parece inevitable ya que potencia el acceso a la información, facilita la interrelación con el usuario, agiliza la manipulación del material audiovisual y aumenta de manera considerable el desarrollo comercial de la información audiovisual. El principal inconveniente del inevitable proceso de digitalización no es la revolución tecnológica ni los cambios en los procesos de producción, sino 
la necesidad de la modificación del rol del documentalista frente a la tecnología, frente a las técnicas documentales y frente a los usuarios.

Los tradicionales subsistemas de gestión documental deben adaptarse a la realidad de los medios de comunicación y a los diferentes soportes documentales y naturaleza de los item empleados. Los subsistemas propios de la gestión documental son el bibliotecario, archivero y documental, subsistemas que deben cambiar y evolucionar a la realidad de la gestión documental audiovisual en las televisiones, implementando un centro de documentación multimedia con subsistemas audiovisual, sonoro, textual y de imagen fija (fotoperiodística).

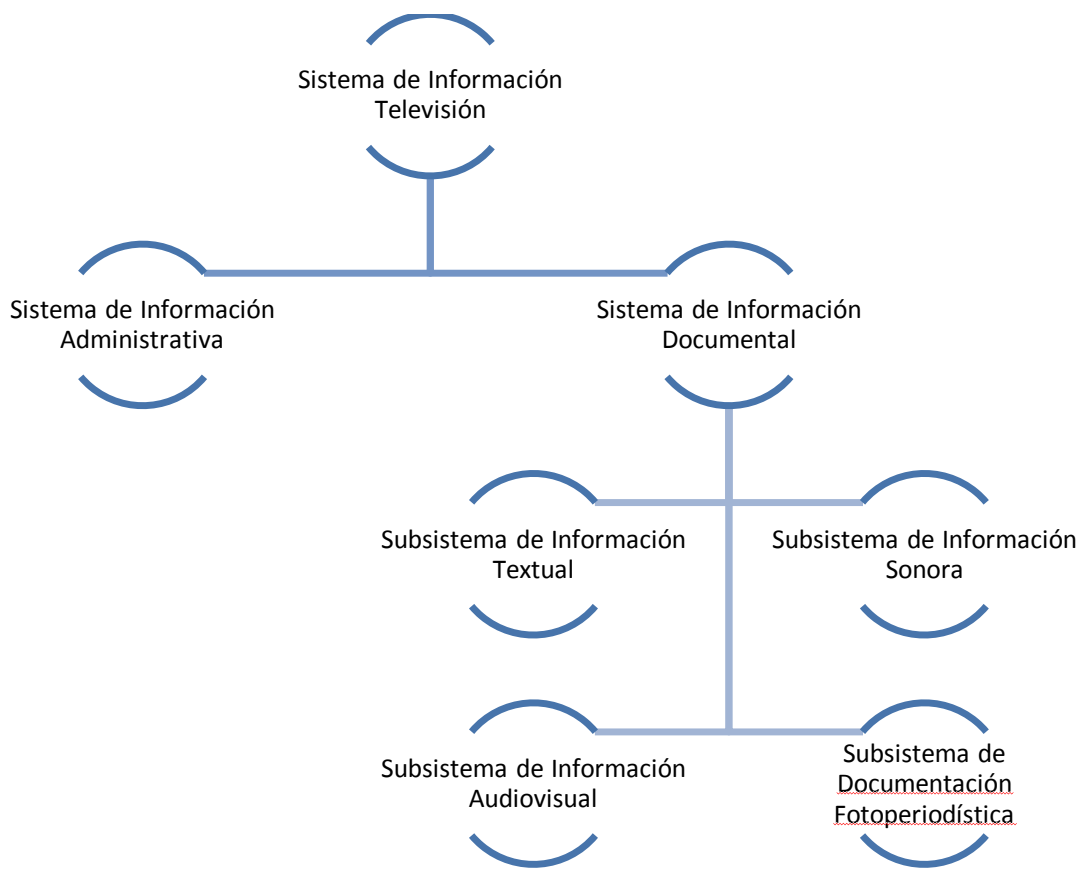

Gráfico 2.

\section{Subsistema de Información Documental Textual}

Este subsistema es necesario en cualquier tipo de unidad de documentación, derivado de la necesidad de contar con información para verificar y contextualizar la noticia que se emite y se recibe por parte del telespectador.

La documentación textual, en soporte papel, informático o cualquier otro, su única definición es ser trasmitida en forma de texto, dejando de lado su forma de reproducción.

Parece inevitable su existencia en los servicios de documentación de las televisiones, aunque habrá que plantearse su alcance en las pequeñas cadenas locales en la que se debe ponderar cuáles son las prioridades 
en estos servicios. Con ello se desea señalar que habrá que determinar, en caso de ser imposible llevar a cabo todas las labores documentales, cuáles de aquellas son susceptibles de ser eliminadas.

La naturaleza audiovisual de la televisión podría plantear que este subsistema no fuera prioritario pero no dejaría de ser un grave error aunque sí que habría que modificar la fórmula de trabajo actual en las grandes televisiones. Parece poco fiable el contar con grandes departamentos que gestionen el subsistema textual derivado del mucho trabajo que es necesario para el control de dicha información, además de existir empresas que elaboran productos ya terminados a los que se podría acceder por medio de la red.

Por lo tanto, el subsistema de gestión de información textual deberá gestionar una serie de documentos, ofreciendo un servicio de referencia, la organización de una biblioteca y hemeroteca, archivo de recortes (antigua "morgue" en muchos centros) y el posibilitar el acceso a la información y a diferentes productos y servicios en línea.

Caldera y García (2004) analizan los servicios que debe ofrecer una intranet para medios impresos, entre los que destacamos la creación de directorios internos y externos; fuentes referenciales, diccionarios y glosarios; bases de datos propias y externas; documentos a texto completo; creación de aplicaciones sencillas para trabajos en grupo; acceso a buscadores de dominio público; información empresarial que defina reglamentos, políticas ideológicas, carteleras de novedades, informes y proyectos; acceso a servicios de pago contratados por la compañía y acceso a otros medios de comunicación.

\section{Subsistema de Información Documental Sonoro}

Se estima necesario el contar con un subsistema documental encargado de la conservación y búsqueda de información sonora para ambientar musicalmente las piezas audiovisuales, pero no es tan necesario contar con una estructura compleja derivado de la utilidad de ese material.

Recordar que el tipo documental que pudiera analizarse en estos subsistemas, propios de los medios radiofónicos, son los efectos, música y palabra (cortes de voz).

Los cortes de voz no parecen muy viables para su conservación derivado de la escasa potencialidad de esta información en televisión, es decir, para qué contar con declaraciones de diferentes personajes si dicha información no va acompañada por la imagen. Rara vez suele ser de utilidad y cuando realmente ha tenido que utilizarse estará integrada en la emisión al ser material importante, por lo que ya no estará conservado y analizado por parte de un subsistema sonoro sino por el audiovisual.

Los efectos sonoros, utilizados en programas de entretenimiento, deben ser analizados y conservados siempre y cuando se cuenten con los derechos. La explotación comercial de material sin contar con los derechos, ya sea de naturaleza audiovisual o sonora, puede acarrear graves problemas para la compañía, problemas que se traducen en sanciones económicas y perdidas de contratos con otros proveedores de información. 
Igualmente se puede acceder a estos efectos sonoros en la red de forma gratuita, siempre y cuando sean de libre utilización; no obstante parece inevitable realizar una labor documental de estos efectos, creando por lo tanto una pequeña librería de sonidos para aquellos que cuenten con un alto potencial de utilización atendiendo a las necesidades y realidades de utilización de estos efectos en el medio. Por lo tanto es necesario realizar una clara selección, con unas políticas coherentes al respecto, no conservando cualquier material, creando así una librería de sonidos útil y ágil. Sería recomendable el análisis de la normativa de Radio Nacional de España (1992).

En último lugar señalar respecto al subsistema sonoro la necesidad relativa de contar con el análisis documental de música, cortes musicales con los que se deberá contar con los derechos de explotación. Contar con este departamento parece oportuno siempre y cuando se seleccione mucho la música que se analiza ya que es válido para el desarrollo de programas de entretenimiento, donde en muchas ocasiones se acompaña el producto audiovisual con música, especialmente instrumental.

Otro producto diferente son los derivados de los programas musicales, los que cuentan con una tipología musical muy clara: directos, entrevistas y videoclips. Estos géneros, aunque musicales, son a todas luces audiovisual y son la adaptación de éstos al formato televisivo, especialmente los videoclips. Este material suele ingresar en las televisiones por el envío promocional de los sellos discográficos por los que sólo se podrán utilizar durante cierto periodo de tiempo.

\section{Subsistema de Información Documental Visual}

Subsistema propio de los medios impresos, carece de utilidad en el Sistema de Información Documental de las cadenas de televisión. Seguramente esta aseveración es un tanto lapidaria y con total seguridad no compartida por la totalidad de los responsables de los departamentos de documentación de las cadenas audiovisuales. De todas maneras, los argumentos son igualmente escuetos: la documentación de imagen fija no es utilizada prácticamente por los periodistas. La documentación visual tiene escaso interés al carecer de movimiento y romper el ritmo del montaje visual de la televisión. Por lo tanto, la utilidad de dicho subsistema nunca debe darlo el documentalista sino el usuario, en este caso el periodista, y el uso de la fotografía prácticamente está en desuso en los medios audiovisuales. Para utilizar el material visual sin movimiento, el sistema de información deberá carecer de material audiovisual.

Cualquier realizador o montador televisivo siempre preferirán material de imagen en movimiento con mala calidad o con escasa duración antes de insertar material de imagen fija. Si analizan detenidamente la utilización de la fototeca o subsistema de imagen fija en las televisiones se observará que las escasas fotografías son aquellas que son cedidas por la Dirección General de la Policía para poder localizar delincuentes o desaparecidos.

No confundir el material propio de este subsistema con material infográfico o con cualquier otro material de postproducción aunque pudiera contar con una imagen fija. Estas imágenes artificiales serán elaboradas cada vez que sea necesario, siendo actualmente muy fácil la creación de librerías de mapas digitales así como de otros productos. 
Por lo tanto, desde aquí se apuesta por la no implementación de este subsistema, lo que ya ha sido planteado y puesto en marcha por algunas cadenas. Los esfuerzos deben desarrollarse sobre los subsistemas que realmente son utilizados por los usuarios y no por aquellos que únicamente engrandecen la potencialidad, pero no el uso, de los departamentos de documentación.

\section{Subsistema de Información Documental Audiovisual}

La naturaleza audiovisual de este medio de comunicación de masas es lo que lo hace atractivo y especial, sentando desde más de cuatro décadas a familias, comunidades y grupos sociales en torno de un electrodoméstico en el que se puede observar un fragmento de la realidad tal y como pudiera ser considerado y visto por éstos. Un medio en el que los principales sentidos, al menos los que más atención captan como la vista y oído, están al servicio de la información, el espectáculo, en definitiva, el entretenimiento. El Homo Videns, en rápida transformación al Homo Digitalis, ha encontrado en la televisión una fórmula de entretenimiento e información, herramienta de fácil consumo por su atractivo audiovisual y tendencia a lo espectacular.

Por lo tanto parece inevitable que el Subsistema de gestión de la información audiovisual sea sin ningún género de dudas el más importante en cualquier sistema de información en las televisiones.

La documentación audiovisual, o de imagen en movimiento, es la piedra angular en este sistema teniendo que analizar dos componentes que no siempre se emiten o se utilizan de forma sincrónica: la imagen y el sonido. Estos dos componentes deben ser analizados por separados así como el significado que de estos productos se extrae de la unión de ambas, que no tiene por qué ser idéntica a lo captado por separado.

Determinemos en primer lugar cual es el objeto de trabajo de este subsistema. Se apuesta por una definición de documentación audiovisual bastante restrictiva en la que tan solo se incluyen los documentos que están compuestos por la imagen y el sonido, y no cada uno de ellos por separado. Se prefiere apostar por el concepto de "imagen en movimiento" para definir el documento analizado en las televisiones, el cual puede estar acompañado de sonido, de forma sincrónica o asíncrona.

Por lo tanto, en el marco de una hipotética estructura orgánica del departamento de documentación el subsistema principal sería el de documentación audiovisual, en el cual deberían integrarse el resto de subsistema aportando información para una mejor utilización de éste y optimización de recursos. Esto sin lugar a dudas no conduce a una nueva fórmula de organización: el centro de documentación multimedia, que integra diferentes subsistemas que, aunque unos tengan prioridad frente a otros, organiza la información en una única estructura centralizada en la que el usuario puede acceder a la información de manera rápida y ágil.

El subsistema de información audiovisual debe ofrecer la posibilidad de acceder de forma digitalizada a la documentación por medio de motores de búsquedas que ofrezcan la posibilidad de recuperar por diferentes aspectos, destacando los onomásticos y los temáticos; es necesario contar con herramientas documentales de descripción ergonómica y ágil, con términos claros y precisos para el usuario, términos que deberán cambiar con la evolución lógica de las modas informativas y del lenguaje periodístico. 


\section{PROCESO DE PRODUCCIÓN DE LA NOTICIA EN TELEVISIÓN}

Fraser Bond (Introducción al periodismo) señala que las rutinas productivas en información televisiva es un reflejo de la escasez de tiempo y de medios en muchos de los casos, priorizando así la obtención de beneficios económicos en un mercado competitivo para la cual resulta imprescindible la racionalización del trabajo.

Las etapas de elaboración de una noticia en un programa informativo variará atendiendo a los autores estudiados, por ello de forma rápida -al no ser parte fundamental pero sí contextualizadora- se va a mostrar las principales etapas de la confección.

Conceptualización. Primera etapa de conocimiento e interpretación correcta del acontecimiento. El acontecimiento llega al periodista por medio de las diferentes fuentes de procedencia de televisión, debiendo interpretarlo por medio del acceso a información de actualidad - teletipos- como por la interrogación a fuentes escritas para valorar la importancia, veracidad y validez de la noticia.

Proceso de narración. La información en televisión no son hechos aislados sino que están en relación con su entorno, así como con una serie de antecedentes y, por lo tanto, con sus consecuentes. Para ello, no debe contextualizarse tan solo con un hecho puntual sino con toda la información que la rodea. Este esfuerzo hace necesario que el periodista interrogue las bases de datos para conocer en mayor profundidad el calado e importancia de la información conforme a otras que han ocurrido con anterioridad, previendo posibles consecuencias.

Noticiabilidad. Una vez conocida la información, así como todas las relaciones con su entorno, se deberá valorar hasta que punto es necesario su estructuración en un lenguaje periodístico para ser posteriormente emitida. Los criterios por los que una información se convierte en noticia no deben ser valorados por un documentalista sino por los profesionales de las Ciencias de la Comunicación, aunque determinar que en muchos casos dependerá de la ideología y tendencia del medio.

Selección o rechazo. Una vez analizada las noticias y las diferentes características que se derivan de su noticiabilidad la noticia debe pasar el filtro nunca reconocido de los intereses ideológicos de la cadena. Otros aspectos a tener en cuenta para la selección o rechazo pueden variar desde las condiciones técnicas a la duración o temática de la información. Igualmente las secciones en un informativo deben estar compensadas en lo que a tiempo de emisión se refiere. Y por supuesto, habrá que contar con los intereses de los telespectadores.

Construcción discursiva. En caso de ser seleccionado la información debe llevarse a cabo la estructuración de la información, articulando imágenes, sonidos y textos verbales (locución o voz en off) todo ello implementado en un espacio y tiempo delimitado. Podrán incluirse tanto material creado por ordenador como elementos externos de grafismo, así como la potencial utilización de material del archivo audiovisual, fotográfico o sonoro.

Compaginación o formato. Una vez montada la noticia vuelve a ser valorado para determinar si el producto audiovisual final es de calidad o, por el contrario, debe ser nuevamente confeccionada. Cada una de las 
noticias es un microdiscurso en el marco de otro global que es todo el informativo, por lo que debe de contar con unas condiciones útiles para ser emitido en el noticiario.

INTEGRADOR DEL SISTEMA DE INFORMACIÓN DOCUMENTAL EN LA CREACIÓN DE LA NOTICIA TELEVISIVA

Partiendo de las fases analizadas con anterioridad, va a desglosarse en qué fases o subfases de la creación de dichos productos audiovisuales se integra el Servicio de Documentación y de qué manera ayuda a crear la información en el gran engranaje de la cadena de montaje de una televisión.

Para ello, se va a desarrollar la explicación por medio de tablas que especifican los diferentes estadios del diseño e implementación de la noticia televisiva, y con posterioridad se indica que subsistema documental participa en la elaboración de la información 


\begin{tabular}{|c|c|c|c|c|}
\hline \multicolumn{3}{|c|}{ PRIMERA FASE } & & \\
\hline Fase & \multicolumn{4}{|c|}{ CONCEPTUALIZACIÓN } \\
\hline \multicolumn{5}{|l|}{ Subfases } \\
\hline \multicolumn{2}{|l|}{ Denominación } & \multicolumn{3}{|c|}{ Contenido } \\
\hline \multicolumn{2}{|c|}{ Acceso a las fuentes } & \multicolumn{3}{|c|}{$\begin{array}{l}\text { Las fuentes de procedencia de la información para los medios de } \\
\text { comunicación son diversas y complejas, siendo de procedencia } \\
\text { geográfica diversa y con indicación que clarifique todos los } \\
\text { elementos relacionados con los derechos de explotación y utilización } \\
\text { del material. } \\
\text { Determinar si la información proviene de fuentes propias o ajenas } \\
\text { podrá solucionar posibles sanciones legales una vez reutilizado el } \\
\text { material. } \\
\text { Importante como fuente de información son las Agencias de } \\
\text { Información, por sus despachos textuales y/o audiovisuales. }\end{array}$} \\
\hline \multicolumn{2}{|c|}{ Primera selección } & \multicolumn{3}{|c|}{$\begin{array}{l}\text { Se realizará una primera selección para valorar la calidad y la valía } \\
\text { temática y visual de la información, determinando así su potencial } \\
\text { de emisión por parte de la cadena. }\end{array}$} \\
\hline \multicolumn{5}{|c|}{ Subsistema documental integrado en la fase } \\
\hline Audiovisual & ? & Sonoro & Textual ? & Fotográfico ? \\
\hline
\end{tabular}

Audiovisual. Aunque escasamente utilizado por parte del personal de las cadenas televisivas, el fondo documental audiovisual puede ser un buen referente como ayuda a la primera selección de la información, determinando si las imágenes son impactantes y novedosas con respecto a informaciones emitidas con anterioridad. Criterio poco utilizado por la gran cantidad de información audiovisual general que implica que la primera selección venga determinada por parámetros lejanos a los señalados con anterioridad.

Textual. Quede aquí evidenciada la importancia del Subsistema de Información Textual desde el momento en que éste cuenta con un importante fondo de diarios de carácter nacional y extranjero. La lectura atenta y minuciosa de los periódicos por parte del personal hace que la toma rápida de decisiones sobre la validez de una información sea más oportuna, acertada y rápida. Por lo tanto, la actualización de conocimiento por parte del periodista debe ser avalado por un buen servicio de documentación textual que le ofrezca información sobre los acontecimientos que ocurren en su entorno social y el entorno noticiable.

\begin{tabular}{|l|l|l|}
\hline \multicolumn{2}{|l|}{ SEGUNDA FASE } & \\
\hline Fase & PROCESO DE NARRACIÓN \\
\hline Subfases & Contenido \\
\hline Denominación & \\
\hline
\end{tabular}




\begin{tabular}{|l|l|}
\hline \multicolumn{2}{|l|}{ TERCERA FASE } \\
Fase & NOTICIABILIDAD / SELECCIÓN-RECHAZO \\
\hline Subfases & Contenido \\
\hline Denominación & $\begin{array}{l}\text { Ahora es el momento de presentar el informe sobre la valía } \\
\text { para la emisión. Para ello, los jefe de sección (nacional, } \\
\text { internacional, deportes, economía, sociedad, ciencia, etc) se } \\
\text { reúnen con el editor del informativo, el cual es el máximo } \\
\text { responsable intelectual del noticiario. }\end{array}$ \\
\hline
\end{tabular}

Conversión en noticia

Una vez determinada su validez habrá que determinar su ubicación en el marco de la emisión del informativo, así como tratamiento y duración.

La determinación de estos aspectos es crucial ya que determina una mayor audiencia potencial dependiendo del lugar ubicado en el informativo, así como el tratamiento que se desee dar sobre el asunto y el tiempo estimado de duración. Toda información que vaya en los titulares cuenta con una audiencia mayor que aquella ubicada cerca de la información económica, con escaso interés por lo general entre las audiencias generalistas.

Asignación de periodistas

Dependiendo de la importancia, se le asignará a la información un número determinado de reporteros e investigadores para que la cubran. Igualmente dependiendo de la valía de la noticia el editor, junto con el jefe de sección, identificará a los periodistas más cualificados para el seguimiento de la información.

Verificación

Nuevamente el equipo de periodistas implicados en el análisis de la información valorará los datos recopilados tanto de las fuentes externas como de la aportada por el Sistema de Información Documental. En caso necesario pueden requerir información de los personajes implicados o de las instituciones afectadas, contactando con éstos antes del envío físico del equipo de periodistas o de la preparación de la información.

\section{Subsistema documental integrado en la fase}


Audiovisual

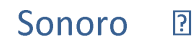

Textual ?

Fotográfico ?

Audiovisual / Textual. Los departamentos de documentación pueden servir de base tanto para la verificación y validación de la información aportada por las fuentes, como para una ampliación de conocimientos de lugares, personas y temas. Los dos departamentos, el audiovisual y el textual, pueden ser utilizados indistintamente atendiendo al tipo de información y a la naturaleza del material a requerir.

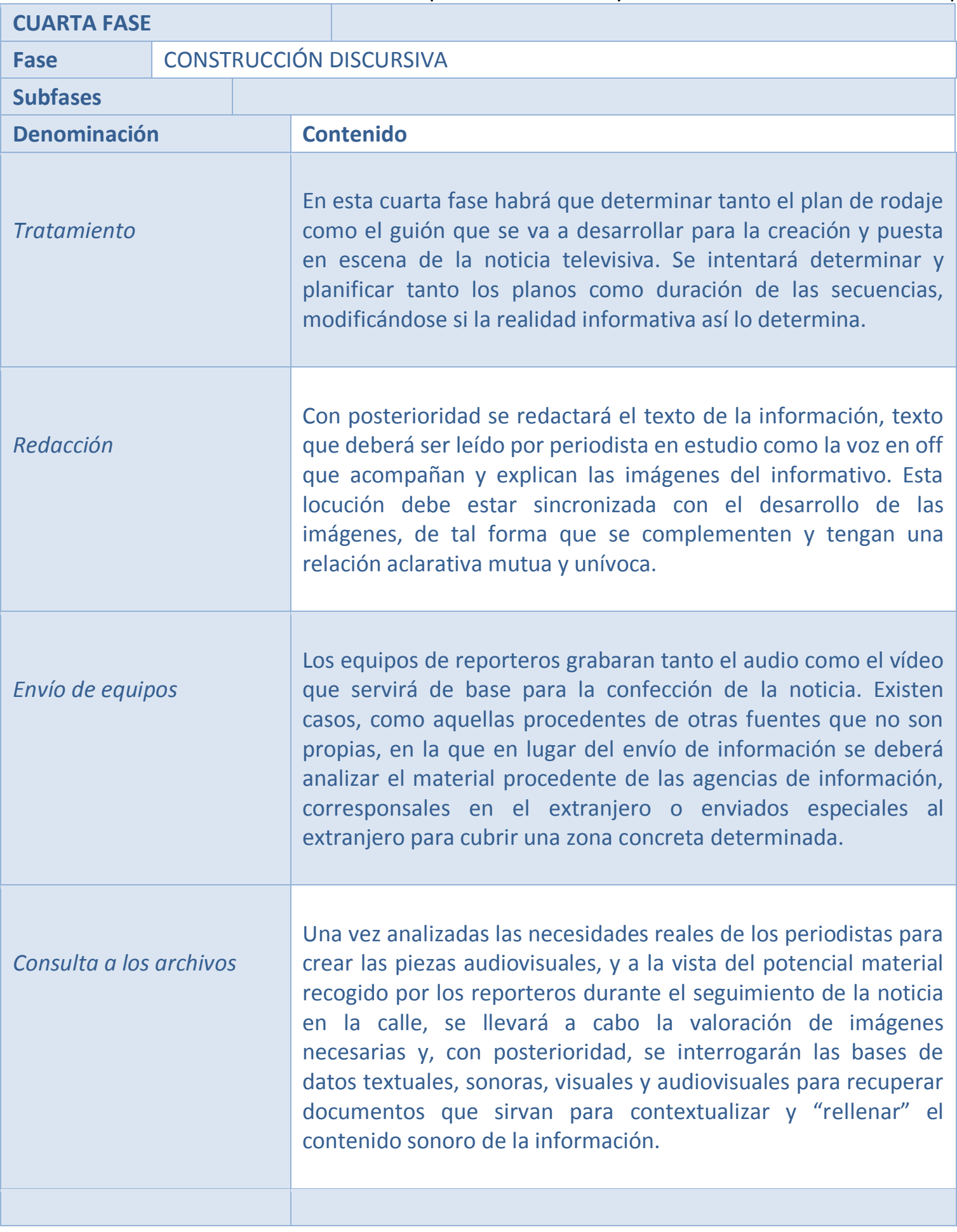

Cuadernos de Documentación Multimedia Vol. 24. 


\begin{tabular}{|c|c|c|c|}
\hline Postproducción & \multicolumn{3}{|c|}{$\begin{array}{l}\text { Una vez finalizado el material visual y sonoro, se le añadirán } \\
\text { todos los elementos identificativos de la cadena por medio de } \\
\text { elementos de postproducción. Igualmente se añadirán gráficos, } \\
\text { efectos y todos cuantos elementos se consideren oportunos } \\
\text { para un mejor entendimiento de la información. }\end{array}$} \\
\hline Visionado información & \multicolumn{3}{|c|}{$\begin{array}{l}\text { Se vuelve a visionar nuevamente todo el material, tanto el } \\
\text { grabado por el personal como todo el de archivo. Se analiza para } \\
\text { detectar posibles carencias y en caso necesario se volvería al } \\
\text { departamento de documentación audiovisual con el fin de volver } \\
\text { a interrogar las bases de datos, recuperando materiales } \\
\text { susceptibles de ser incluido el producto final. }\end{array}$} \\
\hline Montaje audio/video & \multicolumn{3}{|c|}{$\begin{array}{l}\text { Una vez realizado en forma lineal-temporal tanto la imagen } \\
\text { como el sonido de la información, se lleva a cabo el montaje } \\
\text { sincronizando de ambas realidades, dando por terminado el } \\
\text { montaje informativo. }\end{array}$} \\
\hline \multicolumn{4}{|c|}{ Subsistema documental integrado en la fase } \\
\hline Audiovisual ?] & \multicolumn{2}{|c|}{ Sonoro ? } & Fotográfico ? \\
\hline
\end{tabular}

Audiovisual. En esta fase es cuando el archivo audiovisual cobra especial relevancia. Son muchas las noticias de informativos que utilizan imágenes de archivos, más de las que la audiencia puede creer y más de las que se informa por medio de rótulos a los telespectadores. Podría valorarse que más de un tercio del material televisivo cuenta con material de archivo que compone la información. Sin embargo son escasos los montajes de archivos, denominación que reciben aquellas piezas informativas que cuentan con todo el material procedente del fondo documental. Se interrogarán las bases de datos del archivo tanto para localizar y utilizar declaraciones como imágenes de relleno. Normalmente las solicitudes suelen ser solicitudes concretas, de secuencias bien determinadas, lo que dificulta infinitamente la recuperación. Esto acarrea un nivel de tratamiento de documentos audiovisuales más que exhaustiva, pudiendo solucionar solicitudes en las que el usuario pide por ejemplo: "Tony Blair subiendo a un coche, mientras saluda. Imágenes nocturnas", "Puesta de sol en parajes nevados"

Sonoro. Son muchas las opciones que nos puede ofrecer el departamento de documentación sonora. Utilización de efectos sonoros o temas musicales son las opciones más habituales. Aunque suelen ser utilizados en programas de entretenimiento o programas informativos tipo magazine, talk show o reality show, también pueden ser incluidos en noticiarios, temas musicales que acompañan a algunas noticias, especialmente de sociedad, moda o cultural.

Textual. A estas alturas de la confección de la pieza informativa la utilización de documentación textual se sustenta en la contestación puntual de datos, por lo tanto sirve para verificación de información que posteriormente han de ser ofrecidas por la banda sonido de la información. 
Fotográfico. Son escasas las solicitudes de materia al departamento de imagen fija, tanto es así que muchas televisiones carecen de dicho departamento en su organigrama documental. Son muchos los realizadores que prefieren poner imágenes en movimiento de mala calidad o de escasa duración antes de poner imagen fija. El silencio a la radio es lo que la imagen fija a la televisión, siendo por tanto incongruentes con la naturaleza audiovisual del material.

\begin{tabular}{|c|c|c|c|}
\hline \multicolumn{4}{|l|}{ QUINTA FASE } \\
\hline Fase & \multicolumn{3}{|c|}{ COMPAGINACIÓN O FORMATO } \\
\hline \multicolumn{4}{|l|}{ Subfases } \\
\hline Denominación & \multicolumn{3}{|l|}{ Contenido } \\
\hline Revisión & \multicolumn{3}{|c|}{$\begin{array}{l}\text { Durante la subfase de revisión vuelve a visionarse el documento } \\
\text { con el fin de valorar si dicho documento cuenta con la valía formal y } \\
\text { física para que sea emitida por la cadena. No piensen que los } \\
\text { criterios de calidad exigibles son escasos, pudiendo ser mucho los } \\
\text { documentos que vuelven a rehacerse. }\end{array}$} \\
\hline Valoración & \multicolumn{3}{|c|}{$\begin{array}{l}\text { Una vez visionado, el jefe de sección valorará su emisión, } \\
\text { reestructuración o nulidad. En caso de que la parrilla del } \\
\text { informativo haya incluido piezas para las que inicialmente no } \\
\text { estaba adaptada tendrán que eliminarse noticias que inicialmente } \\
\text { contaban con el beneplácito para su exhibición. }\end{array}$} \\
\hline Reestructuración/FIN & \multicolumn{3}{|c|}{$\begin{array}{l}\text { La valoración negativa, tal y como se ha indicado con anterioridad, } \\
\text { conlleva una nueva labor en la que puede recuperarse nuevamente } \\
\text { material del archivo; mientras que si se observa válida para la } \\
\text { emisión las fases de producción habrán finalizado. }\end{array}$} \\
\hline \multicolumn{4}{|c|}{ Subsistema documental integrado en la fase } \\
\hline Audiovisual & 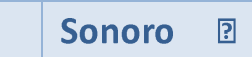 & Textual ? & 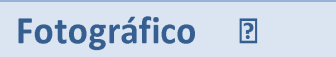 \\
\hline
\end{tabular}

No es utilizado el Sistema de Información Documental, sin embargo es posible que se considere necesaria la consulta nuevamente de las bases de datos para identificar nuevas imágenes a incluir. 


\section{CONCLUSIÓN}

Identificar la importancia de la implementación y diseño de un Sistema de Información Documental en las televisiones con el fin de facilitar y mejorar la creación de los productos informativos audiovisuales.

Dicha necesidad viene avalada por el alto rendimiento que se realiza sobre estos servicios a la vista del porcentaje de utilización como de la variedad tipológica de las consultas planteadas.

Los Sistema de Información Documental se convierten en grandes Centros de Documentación Multimedia donde se encuentran documentos textuales, audiovisuales, textuales y sonoros, documentos que deben adaptarse a los requerimientos de los periodistas para poder recuperar con agilidad y fiabilidad la documentación requerida en breve periodo de tiempo.

Aunque cualquier cadena televisiva podría emitir sin la implantación de un Sistema de Información Documental se estima importante para la calidad, valía, prestigio y credibilidad de la empresa televisiva, siendo un servicio muy valorado por el personal de la empresa por los altos costes de rendimiento, y por las capas directivas de la empresa por la rentabilidad intelectual y económica.

\section{REFERENCIAS}

Bond, F. Fraser (1954). An introduction to journalism: a survey of the fourth estate in all its forms. New York: Macmillan.

Caldera-Serrano, J (2006). Seen and heard: duality at the access point to television database" // Aslib Proceedings: new informative perspective. 58 (4), pp. 30-43

Caldera-Serrano, J (2008). Changes in the management to information in audiovisual archives following digitazation: current and future Outlook// Journal of Librarianship and Information Science. 40 (1) : 13-20.

Caldera-Serrano, J (2014) Resumiendo documentos audiovisuales televisivos: propuesta metodológica // Perspectivas em Ciência da Informação, v.19, n.2, p.147-158.

Caldera-Serrano, J. ; García-de-León, A. (2004) Las intranets como herramientas documental para la prensa escrita" // Hipertext.net, 2,URL (consulted Mar. 2014), http://www.hipertext.net/web/pag226.htm.

Codina, L. (1994) "La naturaleza de la recuperación de información: implicaciones para el diseño de sistemas de información documentales” in IV Jornadas Españolas de Documentación Automatizada. Gijón: Universidad de Oviedo, Servicio de Publicaciones.

McLuhan, H.M. (1962). The Gutenberg Galaxy: the making of typographic man. Toronto: University of Toronto Press.

Radio Nacional de España. Comisión de Técnicos del Archivo Sonoro y Documentación (1992). Normas de catalogación del archivo sonoro de Radio Nacional de España. Madrid : Centro de Formación RTVE. 